Mineralogical Journal, Vol. 7, No. 3, Pp. 262-281, Oct., 1973

\title{
The crystal structure of Banalsite, $\mathrm{BaNa}_{2} \mathrm{Al}_{4} \mathrm{Si}_{4} \mathrm{O}_{16}$, and its relation to the feldspar structure
}

\author{
NOBUHIKO HAGA \\ Mineralogical Institute, Faculty of Science, \\ University of Tokyo, Hongo, Tokyo 113
}

\begin{abstract}
The crystal structure of banalsite, $\mathrm{BaNa}_{2} \mathrm{Al}_{4} \mathrm{Si}_{4} \mathrm{O}_{16}$, has been determined based upon intensity data obtained with the use of a four-circle automatic diffractometer. The unit cell has the dimensions : $a=8.496(2), b=9.983(2)$, $c=16.755(3) \AA$, with four formula units per cell. Space group, Ibam, was assumed and, on refinement, turned out to be correct. The structure is built on a framework formed by the linking of rings of four oxygen-tetrahedra around $\mathrm{Al}$ or Si. Although the mutual orientation of the component tetrahedra in a ring is different from that of the four-membered rings in feldspars, there is a close relationship between the banalsite structure and the feldspar structures. The mean T-O length of one of the two independent tetrahedra in the structure is 1.683 (4) $\AA$, and that of the other 1.680 (4) $\AA$, suggesting that $\mathrm{Si}$ and $\mathrm{Al}$ are, in spite of the ratio of $\mathrm{Al} / \mathrm{Si}=1$, dis. tributed randomly over the tetrahedral sites. Because of such an unexpected result, an attempt was made at refining the structure in space group Iba2, which the structure would possess if Al and Si were perfectly ordered. However, the refinement was not successful in this noncentric space group. $\mathrm{Na}$ and $\mathrm{Ba}$ atoms are respectively coordinated by six and ten oxygen atoms; the mean bond lengths are $2.501(6) \AA$ for $\mathrm{Na}-\mathrm{O}$, and $2.870(4) \AA$ for $\mathrm{Ba}-\mathrm{O}$, both are smaller than corresponding values in other alumino-silicates.
\end{abstract}

\section{Introduction}

Banalsite has a chemical formula closely related to that of celsian (Smith, Bannister and Hey, 1944). If one $\mathrm{Ba}$ in the chemical formula of celsian, $\mathrm{Ba}_{2} \mathrm{Al}_{4} \mathrm{Si}_{4} \mathrm{O}_{16}$, is replaced by two $\mathrm{Na}$, the formula of banalsite results. Banalsite is hence the first example of an alumino-silicate of barium containing sodium as the dominant alkali. In addition to this salient feature in chemistry, the crystals of 
banalsite have, as has been shown by Smith et al. (1944), a strong pseudo-periodicity of $c / 2$, suggesting that they have a subcell of this periodicity. The crystal structure of banalsite accordingly bears a superstructure relation to this subcell. The following is the result of our investigation undertaken with the hope that the elucidation of this structure might shed some light on the crystal chemistry of framework structures of alumino-silicates, especially those of feldspars. Since the procedure of structure analysis which was carried out applying the partial Patterson method (Takéuchi, 1972) has been reported separately (Takéuchi, Kudoh and Haga, 1973), only a brief account of the procedure is given in the present paper to avoide unnecessary duplication.

\section{Experimental}

\section{Materials}

The specimen used in the investigation is from the original locality in the Lleyn Peninsula, Carnarvonshire, England, and was kindly placed at our disposal by Prof. Takeo Watanabe. The chemical composition of this material is well expressed by $\mathrm{BaNa}_{2} \mathrm{Al}_{4} \mathrm{Si}_{4} \mathrm{O}_{16}$ as given by Smith et al. (1944). The results of their chemical analysis are cited in Table 1.

Unit cell and space group

The cell dimensions determined with a four-circle automatic diffractometer (Mo $K \alpha_{1}, \lambda=0.709258 \AA$ ) at $18^{\circ} \mathrm{C}$ are :

$$
a=8.496(2), \quad b=9.983(2), \quad c=16.755(3) \stackrel{\AA}{A} .
$$

Standard deviations given in parentheses are expressed in units of last digit stated. These cell dimensions are essentially the same as those previously reported by Smith et al. (1944). The unit cell contains four of the above molecules, giving a calculated specific gravity of $3.045 \mathrm{~g} / \mathrm{cm}^{3}$ which agrees well with the observed value of $3.065(5)$ 
Table 1. Chemical analysis of banalsite (after Smith, Bannister and Hey, 1944)

\begin{tabular}{lr|ll|c}
\hline \multicolumn{2}{c|}{} & \multicolumn{2}{|c|}{$\mathrm{II}$} & III \\
\hline $\mathrm{SiO}_{2}$ & 34.74 & $\mathrm{Si}$ & $15.2 \pm 0.6$ & 16 \\
$\mathrm{Al}_{2} \mathrm{O}_{3}$ & 31.20 & $\mathrm{Al}$ & $16.1 \pm 0.6$ & 16 \\
$\mathrm{MgO}$ & 1.00 & $\mathrm{Mg}$ & 0.7 & \\
$\mathrm{BaO}$ & 21.99 & $\mathrm{Ba}$ & $3.8 \pm 0.2$ & 4 \\
$\mathrm{CaO}$ & 0.81 & $\mathrm{Ca}$ & 0.4 & \\
$\mathrm{MnO}$ & 0.03 & $\mathrm{Mn}$ & 0.01 & \\
$\mathrm{Na} 2$ & 8.43 & $\mathrm{Na}$ & $7.1 \pm 0.6$ & 8 \\
$\mathrm{~K}_{2} \mathrm{O}$ & 0.66 & $\mathrm{~K}$ & 0.4 & \\
$\mathrm{H}_{2} \mathrm{O}$ & 1.08 & $\mathrm{O}$ & $63.2 \pm 1.2$ & 64 \\
\hline Total & 99.94 & & 106.9 & 108 \\
\hline
\end{tabular}

(I) the weight percentage of oxide form of each atom; (II) the numbers of atoms in the unit cell and (III) the ideal numbers of atoms contained in $4 \mathrm{BaNa}_{2} \mathrm{Al}_{4} \mathrm{Si}_{4} \mathrm{O}_{16}$.

$\mathrm{g} / \mathrm{cm}^{3}$ (Smith et al., 1944).

Observed missing rule of spectra confirmed the possible space: group Ibam or Iba2 which had been proposed by Smith et al. (1944).

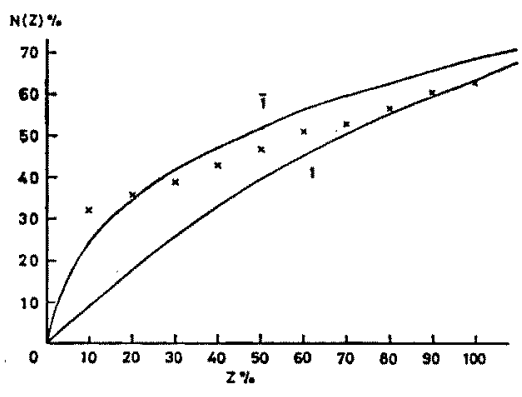

Fig. 1. $N(z)$ plot for all $h k l$ reflections. The curves, $\mathrm{I}$ and 1 , represent the theoritical plots for centric and noncentric structure respectively. The experimental curve is plotted by " $x "$.
The result of the $N(z)$ test (Fig. 1) did not show conclusive evidence whether the structure is. centric or noncentric. Since, however, a test of piezo-electricity made on the device as reported by litaka (1953) did not give definite response, we assumed space group Ibam.

Structure factors

The shape of the crystal used! for intensity measurement was. tabular parallel to (001) and had 
approximate dimensions of $0.1 \times 0.1 \times 0.06 \mathrm{~mm}$. The intensities of a total of 1074 independent reflections up to $\sin \theta=0.50$ were measured with Mo $K \alpha_{1}$ radiation on a four-circle automatic diffractometer. It was observed that among intensities those of the reflections with $l \neq 2 n$ are very weak, suggesting that the crystal has a substructure with a periodicity of $c / 2$. After correction for Lorent $z$ and polarization factors, a set of $\left|F_{0}\right|$ 's were obtained. No corrections were made for absorption and extinction effect.

\section{Analysis}

\section{Method}

Because of the existence of the above mentioned substructure, the entire structure of banalsite bears a superstructure relation to this substructure, prohibiting straightforward determination of structure by ordinary means. Banalsite thus offers an example to test the power of the partial Patterson method which has been developed by Takéuchi (1972) aiming at direct solution of superstructure of moderate complexity. Although the detail of the procedure applied for this particular case of banalsite has been reported elsewhere (Takéuchi, Kudoh and Haga, 1973), a brief account is given here for the convenience of the subsequent discussions.

The analysis was carried out in two steps. First, the Fourier synthesis of the substructure having the periodicity of $c / 2$ was calculated based upon the probable signs of $F_{h k L}$ 's in terms of the contribution of barium atoms, which occupy a set of special positions in the subcell (where $L$ represents even numbers in $l$ ). Since the substructure has space group C $\mathrm{mmm}$, which is naturally of higher order than that of the true structure, there occur in the Fourier synthesis peaks which do not represent true atomic locations. In other words, the synthesis offers merely the electron density of the true structure averaged over subcells. The electron density of the substructure was further confirmed by an $E$-map which was syn- 
Table 2. Atomic coordinates derived by the partial Patterson method. Asterisk “*” indicates atoms constituting the substructure.

\begin{tabular}{l|l|l|l}
\hline & $x$ & $y$ & \multicolumn{1}{|c|}{$z$} \\
\hline $\mathrm{Ba} *$ & 0.0 & 0.0 & 0.25 \\
$\mathrm{Na}$ & 0.04 & 0.17 & 0.5 \\
$\mathrm{~T}(1)$ & 0.22 & 0.45 & 0.41 \\
$\mathrm{~T}(2)$ & 0.07 & 0.31 & 0.16 \\
$\mathrm{O}(1)$ & 0.22 & 0.01 & 0.0 \\
$\mathrm{O}(2)^{*}$ & 0.0 & 0.29 & 0.25 \\
$\mathrm{O}(3)$ & 0.12 & 0.13 & 0.12 \\
$\mathrm{O}(4)$ & 0.06 & 0.35 & 0.41 \\
$\mathrm{O}(5)$ & 0.22 & 0.42 & 0.15 \\
\hline
\end{tabular}

thesized employing phases determined by the symbolic addition procedure applied to $\left|E_{h k L}\right|$ 's (Karle and Karle, 1966).

Then, as the next step, we computed the partial Patterson map based only upon the weak $l$-odd reflections. This particular function was readily interpreted as discussed elsewhere (Takéuchi, Kudoh and Haga, 1973), and its result combined with that of the first step revealed all true locations of atom. The atomic parameters thus. are given in Table 2 .

\section{Refinement}

The structure was refined using the full-matrix least-squares: program, ORFLS (Busing, Martin and Levy, 1962). The atomic coordinates as given in Table 2 and over-all temperature factor of 0.854 were used as starting parameters. The atomic scattering factors for each atom were those giver, by Thomas, Umeda and King (International Tables for X-ray Crystallography. Vol. 3, 1962). No attempts were made to distinguish between $\mathrm{Si}$ and $\mathrm{Al}$ atoms during the refinement. They were both given symbol $\mathrm{T}$ and $1 / 2$ $\left(f_{S i}+f_{A l}\right)$ was used as the atomic scattering curve for $\mathrm{T}$ atoms. The weighting scheme used was as follows: 


$$
\begin{array}{ll}
w=1 /\left(11.96+\left|F_{0}\right|+0.00268\left|F_{0}\right|^{2}\right) & \text { when }\left|F_{0}\right|>0 ; \\
w=1 / 1000 & \text { when }\left|F_{0}\right|=0 .
\end{array}
$$

The value of $R$, which is defined as $R=\left(\Sigma|| F_{0}|-| F_{c}||\right) / \Sigma\left|F_{0}\right|$, was 0.284 before the first cycle of the refinement. After 9 cycles of the refinement the $R$ value decreased to 0.058 . Since it was judged this model was highly probable, the anisotropic temperature factors were introduced. After 6 cycles of computations, the refinement was converged to give an $R 0.037$. $^{*}$ Although it is thought that the low $R$ value will highly secure the accuracy of atomic parameters, $\mathrm{Al}$ and $\mathrm{Si}$ atoms in the resulting framework structure are distributed at random in spite of the ratio of $\mathrm{Al} / \mathrm{Si}=1$. Because of this unexpected result, an attempt was made at refining the structure in space group Iba2, which the structure would possess if $\mathrm{Al}$ and $\mathrm{Si}$ are completely ordered. As initial atomic parameters, those given in Table 2 were used except that the origin was shifted along the $c$-axis by 0.1234 . The same over-all temperature factors. mentioned above were used. After more than ten cycles of computations, we obtained a value of $R=0.041$. However anisotropic temperature factors of one of the $T$ atoms and some of the $O$ atoms became negative. This result could not be improved by any means. Taking account of the fact that the material did not show piezoelectricity, we therefore decided to assume the centric structure discussed in the following paragraph. The final atomic coordinates. and anisotropic thermal parameters are listed in Table 3.

\section{Discussion of the structure}

Building scheme of the framework

The $a$-axis projection of the crystal structure is given in Figs. 2 and 3 . The structure is built on a framework which is composed

* A copy of the $F_{0}-F_{c}$ table will be obtained from the author upon request. 
Table 3a. Final atomic coordinates of banalsite.

\begin{tabular}{l|l|l|l}
\hline & \multicolumn{1}{|c|}{$x$} & \multicolumn{1}{|c|}{$y$} & \multicolumn{1}{|c}{$z$} \\
\cline { 2 - 3 } $\mathrm{Ba}$ & 0.0 & 0.0 & 0.25 \\
$\mathrm{Na}$ & $0.0422(4)$ & $0.1745(4)$ & 0.5 \\
$\mathrm{~T}(1)$ & $0.2283(2)$ & $0.4429(2)$ & $0.4067(1)$ \\
$\mathrm{T}(2)$ & $0.0754(2)$ & $0.3095(2)$ & $0.1586(1)$ \\
$\mathrm{O}(1)$ & $0.2143(7)$ & $0.0153(6)$ & 0.0 \\
$\mathrm{O}(2)$ & 0.0 & $0.2929(6)$ & 0.25 \\
$\mathrm{O}(3)$ & $0.1254(5)$ & $0.1533(4)$ & $0.1289(3)$ \\
$\mathrm{O}(4)$ & $0.0618(5)$ & $0.3533(4)$ & $0.4082(3)$ \\
$\mathrm{O}(5)$ & $0.2238(5)$ & $0.4212(4)$ & $0.1534(3)$ \\
\hline
\end{tabular}

Table 3b. Thermal parameters of banalsite.

\begin{tabular}{l|c|c|c|r|r|r|r}
\hline & $B\left(\AA^{2}\right)$ & $\beta_{11}$ & $\beta_{22}$ & \multicolumn{1}{|c|}{$\beta_{33}$} & $\beta_{12}$ & \multicolumn{1}{|c|}{$\beta_{13}$} & \multicolumn{1}{|c|}{$\beta_{23}$} \\
\hline $\mathrm{Ba}$ & $0.86(2)$ & $34.1(7)$ & $16.4(5)$ & $6.9(2)$ & 0.0 & 0.0 & 0.0 \\
$\mathrm{Na}$ & $1.49(15)$ & $46.7(44)$ & $26.8(31)$ & $14.0(13)$ & $-5.4(31)$ & 0.0 & \multicolumn{1}{c}{0.0} \\
$\mathrm{~T}(1)$ & $0.77(6)$ & $27.4(18)$ & $14.8(13)$ & $4.5(5)$ & $-3.9(14)$ & $0.8(8)$ & $-0.5(7)$ \\
$\mathrm{T}(2)$ & $0.92(6)$ & $19.6(18)$ & $16.6(12)$ & $4.8(5)$ & $-1.9(14)$ & $1.3(8)$ & $-0.3(7)$ \\
$\mathrm{O}(1)$ & $0.71(20)$ & $26.3(67)$ & $42.5(61)$ & $4.9(16)$ & $1.0(53)$ & 0.0 & 0.0 \\
$\mathrm{O}(2)$ & $0.95(21)$ & $53.4(75)$ & $25.1(48)$ & $9.0(19)$ & 0.0 & $-2.8(42)$ & 0.0 \\
$\mathrm{O}(3)$ & $0.96(15)$ & $25.1(50)$ & $12.5(31)$ & $13.8(16)$ & $11.7(33)$ & $3.8(23)$ & $-0.4(18)$ \\
$\mathrm{O}(4)$ & $1.21(16)$ & $54.8(56)$ & $16.0(33)$ & $8.0(14)$ & $-6.0(37)$ & $3.2(24)$ & $-3.2(17)$ \\
$\mathrm{O}(5)$ & $0.73(14)$ & $21.5(49)$ & $29.5(37)$ & $10.2(13)$ & $-12.8(35)$ & $3.1(22)$ & $2.2(19)$ \\
\hline
\end{tabular}

Standard deviations given in parenthesis expressed in units of last digit stated. $\beta_{11}, \ldots \ldots, \beta_{23}\left(\times 10^{-4}\right)$ are coefficients in the expression $\exp \left[-\left(h^{2}\right.\right.$ $\left.\left.\times \beta_{11}+k^{2} \beta_{22}+\ldots \ldots \ldots+2 k l \beta_{23}\right)\right]$. These parameters are slightly different from intermediate values reported previously (Takéuchi, Kudoh and Haga, 1973).

of tetrahedral groups of oxygens around silicon and aluminum sharing every corner with neighbouring groups. The links of the framework consist of rings of four tetrahedra whose configuration is different from the four membered rings of tetrahedra in feldspar or paracelsian. 
The general building scheme of the framework may best be explained if we divide it into layers formed by the four membered rings of tetrahedra. Thus, Fig. 5 shows a layer which is bounded, in Fig. 2, by $z=$ 0.75 and $z=1.0$, but projected along the $c$-axis. As will be observed in Fig. 5, the apices of the tetrahedra of each ring point up and down alternately unlike those of the tetrahedra in the rings of feldspar. The apices of tetrahedra represented by $R$ (Fig. 5) are in a mirror plane at $z=1.0$ and those represented by $G$ (Fig. 5) are in an $n$ glide plane at $z=0.75$. The layers into which an

Fig. 2. The $a$-axis projection of banalsite. Reflection planes normal to the $c$-axis are at $z=0$ and $1 / 2$, and $n$ glide planes also normal to the $c$-axis are at $z=1 / 4$ and $3 / 4$. The poly. hedral groupings of oxygen around a sodium and a barium are indicated by broken bonds.

Fig. 3. The $a$-axis projection of banalsite showing anisotropic thermal motion.

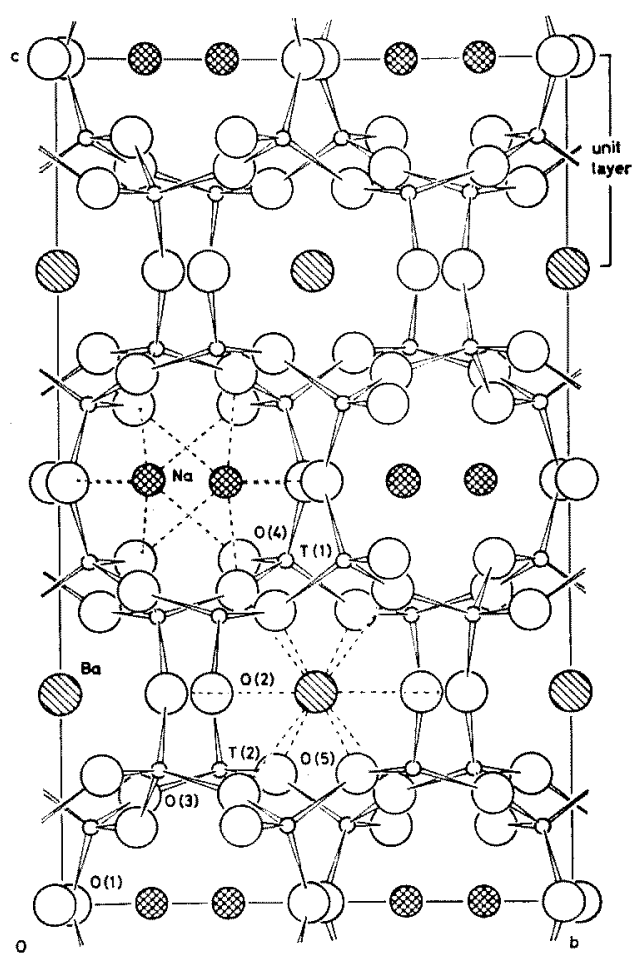

Fig. 2.

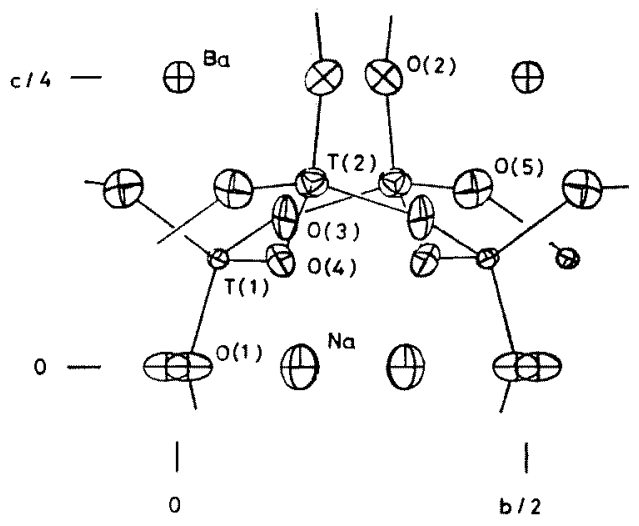

Fig. 3. 

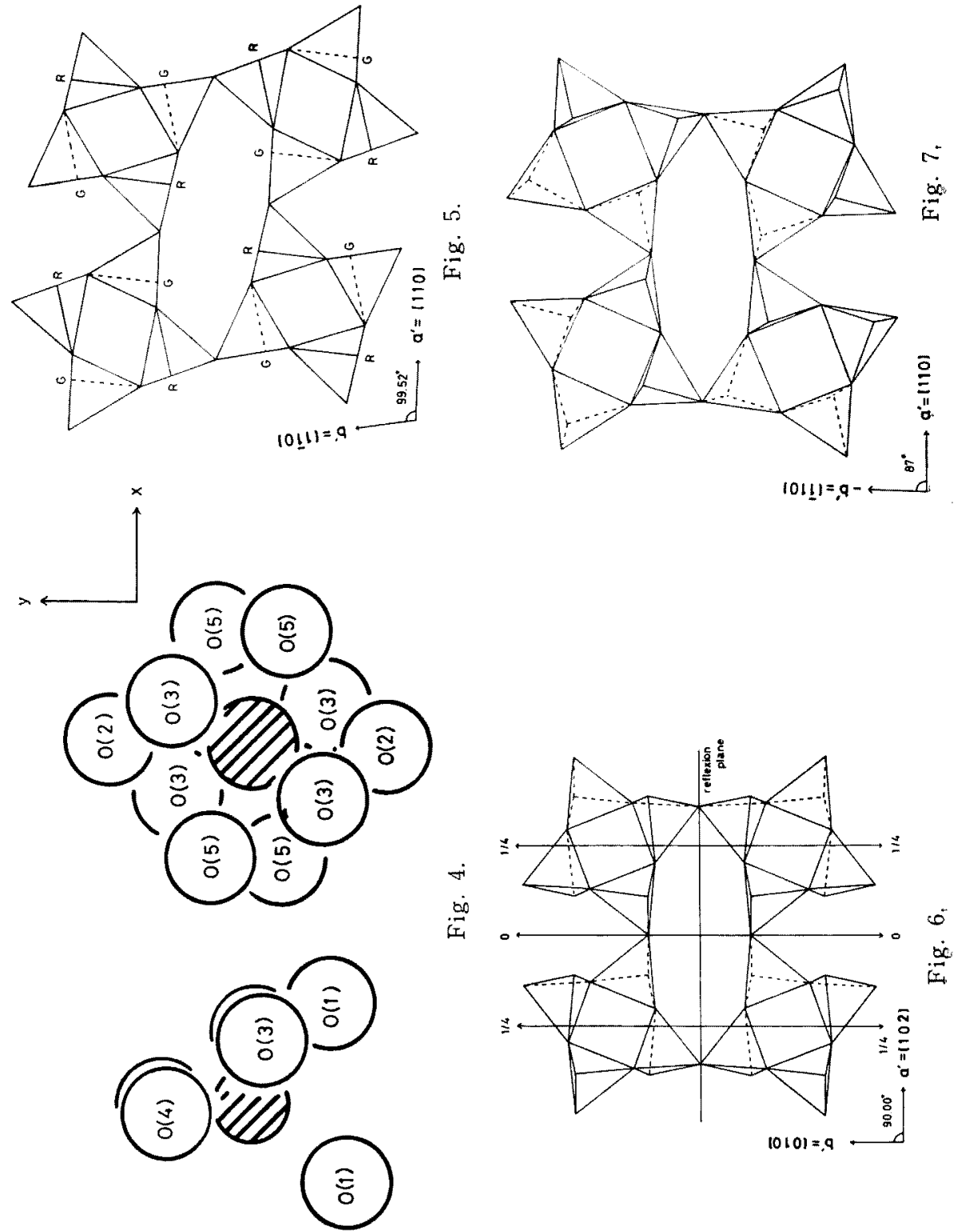

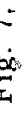

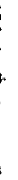

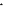


unit layer in Fig. 5 is transformed by the mirror and the $n$ glide operations by turns are arranged parallel to (001) plane having the above apices in common. This way of looking at the structure of

Table 4a. Bond lengths and valence sums, V.

\begin{tabular}{|c|c|c|c|c|c|}
\hline & $\mathrm{Ba}$ & $\mathrm{Na}$ & $T(1)$ & $\mathrm{T}(2)$ & V \\
\hline$O(1)$ & $\begin{array}{ll}0 & 0\end{array}$ & $\begin{array}{lc}1 & 1 \\
2 . & 697(7) \\
1 & 1 \\
\text { 2. } & 393(7)\end{array}$ & $\begin{array}{l}2 \quad 1^{*} \\
\text { 1. } 689(3)\end{array}$ & $\begin{array}{ll}0 & 0\end{array}$ & 2. 039 \\
\hline $\mathrm{O}(2)$ & $\begin{array}{lc}1 & 2 \\
2 . & 923(6)\end{array}$ & $0 \quad 0$ & $0 \quad 0$ & $\begin{array}{l}21 \\
1.669(2)\end{array}$ & 1. 967 \\
\hline$O(3)$ & $\begin{array}{l}1 \\
\text { 2. } \\
757(4)\end{array}$ & $\begin{array}{lc}1 & 2 \\
2 . & 594(5)\end{array}$ & $\begin{array}{l}1 \\
1.680(4)\end{array}$ & $\begin{array}{l}1 \quad 1 \\
1.691(4)\end{array}$ & 2. 120 \\
\hline$O(4)$ & $0 \quad 0$ & $\begin{array}{lc}1 & 2 \\
2.363(5)\end{array}$ & $\begin{array}{lc}1 & 1 \\
1.674(5)\end{array}$ & $\begin{array}{lc}1 & 1 \\
1.674(4)\end{array}$ & 1. 982 \\
\hline$O(5)$ & $\begin{array}{l}\frac{1}{2} .956(4) \\
\text { L }\end{array}$ & $0 \quad 0$ & $\begin{array}{lc}1 & 1 \\
1.690(5)\end{array}$ & 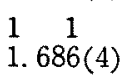 & 1. 896 \\
\hline mean & 2. 870 & 2.501 & 1. 683 & 1. 680 & \\
\hline V & 2. 000 & 1.000 & 3. 500 & 3. 500 & \\
\hline
\end{tabular}

* These two integers mean that $O(1)$ atom is joined to two equivalent $T(1)$ atoms and $T(1)$ atom is joined to an $O(1)$ atom.

Table 4b. T-O-T angles of banalsite.

\begin{tabular}{cc}
\hline $\mathrm{T}(1)-\mathrm{O}(1)-\mathrm{T}(1)$ & $135.35(38)$ \\
$\mathrm{T}(2)-\mathrm{O}(2)-\mathrm{T}(2)$ & $168.57(42)$ \\
$\mathrm{T}(1)-\mathrm{O}(3)-\mathrm{T}(2)$ & $144.84(26)$ \\
$\mathrm{T}(1)-\mathrm{O}(4)-\mathrm{T}(2)$ & $135.92(30)$ \\
$\mathrm{T}(1)-\mathrm{O}(5)-\mathrm{T}(2)$ & $125.31(26)$ \\
\hline
\end{tabular}

Fig. 4. Sodium coordination group viewed along $c$-axis (left) and barium coordination group viewed along $c$-axis (right).

Fig. 5. A unit layer of banalsite formed by four-membered rings of tetrahedra; a view along the $c^{\prime}(=-c)$-axis. The apices $\mathrm{R}$ and $\mathrm{G}$ are respectively on the mirror and glide plane.

Fig. 6. The projection on the $\left(a^{\prime}, b^{\prime}\right)$ plane of the unit layer of sanidine.

Fig. 7. The $c^{\prime}$-axis projection of the unit layer of paracelsian. 
banalsite may be applied to feldspar structures, providing a convenient means to compare these structures. We shall further discuss this point later.

\section{Characteristics of tetrahedra}

The unit cell of banalsite contains $16 \mathrm{Al}$ atoms and $16 \mathrm{Si}$ atoms. Since two independent 16 -fold sites are available for $\mathrm{T}$ atoms, it was expected that $\mathrm{Al}$ and $\mathrm{Si}$ atoms be arranged in an ordered fashion. However, the mean $\mathrm{T}-\mathrm{O}$ distances of the two sets of tetrahedra are the same within standard deviations. The distances are 1.683(4) $\AA$ for $T(1)-O$ and $1.680(4) \AA$ for $T(2)-O$ (Table 4).

It has been empirically shown that $\mathrm{Si}-\mathrm{O}$ and $\mathrm{Al}-\mathrm{O}$ bond lengths are closely given by 1.61 and $1.75 \AA$ respectively (Smith and Bailey, 1963), although Jones (1968) has proposed more precise values of $1.604 \AA$ for $\mathrm{Si}-\mathrm{O}$, and $1.760 \AA$ for $\mathrm{Al}-\mathrm{O}$. In either case, the mean of the $\mathrm{Si}-\mathrm{O}$ and $\mathrm{Al}-\mathrm{O}$ bond lengths is well represented by a value of $1.68 \AA$. As a matter of fact, over-all means of the $\mathrm{T}-\mathrm{O}$ bond lengths of the framework structures having the $\mathrm{Al} / \mathrm{Si}$ ratio of unity have been found to be very close to $1.68 \AA$. Therefore, the mean bond length for each tetrahedron of banalsite suggests that $\mathrm{Si}$ and $\mathrm{Al}$ are randomly distributed over the tetrahedral sites. The $\mathrm{Al} / \mathrm{Si}$ disorder necessarily implies that there occur in the framework the links of the $\mathrm{Al}-\mathrm{O}-\mathrm{Al}$ type. If we locates $\mathrm{Si}$ in the $\mathrm{T}(1)$ site and $\mathrm{Al}$ in $T(2)$ or vice versa, it can be readily shown that there occur by symmetry in the framework, links of the above type as long as we assume the centric space group. This situation is somewhat annoying in view of the generally accepted "aluminum-avoidance rule" (Loewenstein, 1954). In related structures such as anorthite (Megaw, Kempster and Radoslovich, 1962; Wainwright and Starky, 1971), celsian (Newnham and Megaw, 1960) and paracelsian (Bakakin and Belov, 1960), the tetrahedral cations are ordered. Even in the monoclinic phase of $\mathrm{CaAl}_{2} \mathrm{Si}_{2} \mathrm{O}_{8}$ formed by a rapid cooling of a melt, the 
structure has a framework in which $\mathrm{Al}$ and $\mathrm{Si}$ are completely ordered (Takéuchi, Haga and Ito, 1973). These facts may suggest that the centric structure of banalsite may be the result of a submicroscopic twinning of the structure having noncentric space group. Iba2, in which the tetrahedral cations are ordered. Such a situation. has been observed in the structure of monoclinic $\mathrm{CaAl}_{2} \mathrm{Si}_{2} \mathrm{O}_{8}$ (Takéuchi, Haga and Ito, 1973). However, no evidence of this situation. has so far been observed for banalsite. In Table 4, T-O bond. lengths are given together with cation-to-oxygen distances, bond.

Table 5. The tetrahedral edge strains $\Delta \mathrm{x}(\AA)$ and the $\mathrm{O}-\mathrm{T}-\mathrm{O}$ angle strains $\Delta \theta$ (degrees)

\begin{tabular}{|c|c|c|c|c|}
\hline & & & $\Delta \mathrm{x}$ & $\Delta \theta$ \\
\hline \multirow[t]{5}{*}{ (1) } & $T(1)$ & $\mathrm{O}(3)-\mathrm{O}(1)$ & -0.077 & -4.65 \\
\hline & $T(1)$ & $\mathrm{O}(3)-\mathrm{O}(5)$ & -0.068 & -4.19 \\
\hline & $T(2)$ & $O(3)-O(2)$ & -0.065 & -3.51 \\
\hline & $T(2)$ & $O(3)-O(4)$ & -0.120 & -6.81 \\
\hline & & mean & -0.083 & -4.79 \\
\hline \multirow[t]{3}{*}{ (2) } & $\mathrm{T}(1)$ & $O(1)-O(5)$ & +0.040 & +1.64 \\
\hline & $T(2)$ & $O(2)-O(4)$ & +0.022 & +2.39 \\
\hline & & mean & +0.031 & +2.01 \\
\hline \multirow[t]{5}{*}{ (3) } & $T(1)$ & $O(3)-O(4)$ & -0.017 & -0.51 \\
\hline & $T(1)$ & $O(1)-O(4)$ & +0.029 & +1.78 \\
\hline & $\mathrm{T}(2)$ & $O(3)-O(5)$ & +0.085 & +4.54 \\
\hline & $\mathrm{T}(2)$ & $O(2)-O(5)$ & +0.060 & +4.11 \\
\hline & & mean & +0.039 & +2.48 \\
\hline \multirow[t]{3}{*}{ (4) } & $T(1)$ & $O(4)-O(5)$ & +0.086 & +5.28 \\
\hline & $T(2)$ & $O(4)-O(5)$ & -0.020 & -1.19 \\
\hline & & & +0.033 & +2.05 \\
\hline
\end{tabular}

The tetrahedral edge strains and the $\mathrm{O}-\mathrm{T}-\mathrm{O}$ angle strains are the deviations from regular tetrahedron with $\mathrm{T}-\mathrm{O}$ distance, $1.682 \AA$. Two $\mathrm{O}$ atoms in $\mathrm{O}-\mathrm{T}-\mathrm{O}$ in group (1) are bonded more than three large cations in the opposite side of the $T$ atom, and in group (2), two large catiens. In groups (3) and (4), any $O$ atom has no bondings with the large cation in the opposit side of the $\mathrm{T}$ atom, especially edges in (4), are internal edges of four membered rings shown in Fig. 5. 
angles at $\mathrm{O}$, and valence sums. It will be observed in this table that $\mathrm{T}-\mathrm{O}$ bonds vary from $1.669(2) \AA$ to $1.690(4) \AA$. The smallest bond length which occurs between $T(1)$ and $T(2)$ will primarily be ascribed to the large bond angle of $168.57^{\circ}$ at the $\mathrm{O}(2)$ atom. On the other hand, the large value of $1.691 \AA$ observed for the $\mathrm{T}(2)-\mathrm{O}(3)$ bond is obviously related to the larger contribution of cations to the valence sum at $O(3)$.

The strains of the angles at $T$, and tetrahedron edge strains are listed in Table 5. The former gives the distortion of individual angles at $T$ from the regular tetrahedral angle, and the latter that of the deviations from the edge length of a regular tetrahedron (2.747A for the one having $\mathrm{T}-\mathrm{O}=1.682 \AA$ ). The largest negative strain as observed for the edge $O(3)-O(4)$ is undoubtedly due to second nearest neighbour interaction between $\mathrm{T}(2)$ and $\mathrm{Na}$. On the other hand, it should be noted that the large positive strains occur at the edges which form a quadrilateral around the center of each four-membered ring. Such a trend of tetrahedral bond-angle strains is in line with that found in monoclinic $\mathrm{CaAl}_{2} \mathrm{Si}_{2} \mathrm{O}_{8}$ (Takéuchi, Haga and Ito, 1973).

Environment of $\mathrm{Na}$ atoms

In banalsite the $\mathrm{Na}$ atom is irregularly coordinated by six oxygen atoms (Table 4, Fig. 4). The average value of the six $\mathrm{Na}-\mathrm{O}$ distances is $2.501 \AA$ which is fairly small as compared with those of other framework structure bearing $\mathrm{Na}$ atoms, for example, $2.57 \AA$ and $2.60 \AA$ for low albite and high albite (Ribbe, Megaw, Taylor,

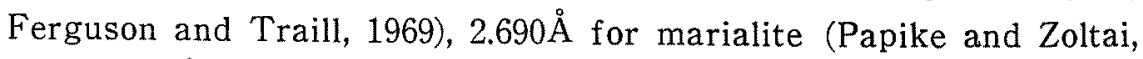
1965), $2.57 \AA$ for natrolite (Meier, 1960), 2.61 for nepheline (Hahn

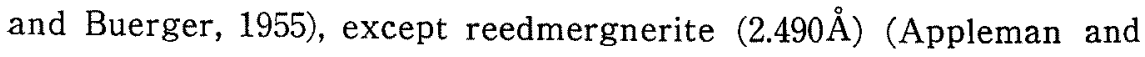
Clark, 1965). The closest $\mathrm{Na}-\mathrm{Na}$ distance and the longest diagonal O-O distance in banalsite are $3.556 \AA$ and $4.493 \AA$ respectively, which compare with $3.92 \AA$ and $5.59 \AA$ for low albite (Ribbe et al., 1969) and 
$3.622 \AA$ and $5.275 \AA$ for reedmergnerite (Appleman and Clark, 1965). If we consider that the framework of banalsite is similar to that of feldspar, and yet must accomodate 1.5 times as many cations as feldspar, it is reasonable that the volume available for cations will be smaller in banalsite than in feldspar. Not only the polyhedra formed by oxygens around $\mathrm{Na}$, but those around $\mathrm{Ba}$ are also smaller than those of other alumino-silicates containing $\mathrm{Ba}$. In contrast to this, the smaller atomic distances in reedmergnerite can simply be ascribed to the shrinkage of the framework due to substitution of small boron atoms for larger aluminum in the feldspar structure.

The isotropic temperature factor for the $\mathrm{Na}$ atom just before introducing the anisotropic ones is $1.49 \AA^{2}$, the final anisotropic temperature parameters are listed in Table 3 . There is no evidence for the presence of extreme anisotropic thermal motion associated with the $\mathrm{Na}$ atoms as found in low and high albite (Williams and Megaw, 1963, Ribbe et al., 1969). The value of $1.49 \AA^{2}$ is considered to be reasonable as compared with $1.22 \AA^{2}$ for reedmergnerite (Appleman and Clark, 1965) and $1.12 \AA^{2}$ for natrolite (Meier, 1960).

Environment of $\mathrm{Ba}$ atoms

The $\mathrm{Ba}$ atom is coordinated by ten $\mathrm{O}$ atoms within the range of $3.0 \AA$ in banalsite (Fig. 4). Eight of the ten oxygen atoms basically form a distorted square antiprism. The interatomic distances of $\mathrm{Ba}-\mathrm{O}$ polyhedra are given in Table 4 . The mean of the closest ten $\mathrm{Ba}-\mathrm{O}$ distances is $2.870 \AA$ which is smaller than celsian : $2.971 \AA$ (Newnham and Megaw, 1959), hexagonal $\mathrm{BaAl}_{2} \mathrm{Si}_{2} \mathrm{O}_{8}: 2.89 \AA$ (Takéu-

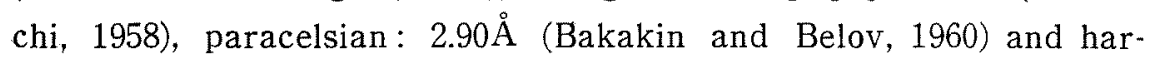
motome: $3.02 \AA$ (Sadanaga, Marumo and Takéuchi, 1961). There is no evidence suggesting the anisotropism of the $\mathrm{Ba}$ atoms as found in celsian (Newnham and Megaw, 1960).

Relation to the feldspar structures

So far as the cell dimensions are concerned, banalsite has, in 
appearence, no structural relation with feldspars. However, if the axes are transformed in a manner outlined by Smith et al. (1944) and compared with those of the large face centered cell (Taylor, 1933) of sanidine (Philips and Ribbe, 1973), we notice a close similarity. The dimensions of the transformed cells are compared below: sanidine

$$
\begin{array}{lll}
a^{\prime}=[102]=13.100 & b^{\prime}=[010]=13.015 & c^{\prime}=[\overline{100}]=8.539 \AA \\
\alpha^{\prime}=90^{\circ} & \beta^{\prime}=99.88^{\circ} & \gamma^{\prime}=90^{\circ}
\end{array}
$$

banalsite

$$
\begin{array}{lll}
a^{\prime}=[110]=13.109 & b^{\prime}=[1 \overline{1} 0]=13.109 & 1 / 2 c^{\prime}=-1 / 2[001]=8.378 \AA \\
\alpha^{\prime}=90^{\circ} & \beta^{\prime}=90^{\circ} & \gamma^{\prime}=99.52^{\circ}
\end{array}
$$

The above cell dimensions of sanidine are calculated from the cell dimensions of Philips and Ribbe (1973). The relation of this large cell of banalsite to its original cell is given by

$$
\left(\begin{array}{r}
a^{\prime} \\
b^{\prime} \\
1 / 2 c^{\prime}
\end{array}\right)=\left(\begin{array}{rrr}
1 & 1 & 0 \\
1 & -1 & 0 \\
0 & 0 & -1 / 2
\end{array}\right)\left(\begin{array}{c}
a_{b} \\
b_{b} \\
c_{b}
\end{array}\right)
$$

And the relation of the face centered cell of sanidine to its original cell is written :

$$
\left(\begin{array}{l}
a^{\prime} \\
b^{\prime} \\
c^{\prime}
\end{array}\right)=\left(\begin{array}{rrr}
1 & 0 & 2 \\
0 & 1 & 0 \\
-1 & 0 & 0
\end{array}\right)\left(\begin{array}{l}
a_{s} \\
b_{s} \\
c_{s}
\end{array}\right)
$$

where, suffixes " $b$ " and " $s$ " stand for banalsite and sanidine respectively. If the large cell of banalsite is supposed to be similar to that of sanidine, the following relation can be deduced from (1) and (2): 


$$
\left(\begin{array}{l}
a_{b} \\
b_{b} \\
c_{b}
\end{array}\right)=\left(\begin{array}{ccc}
1 / 2 & 1 / 2 & 1 \\
1 / 2 & -1 / 2 & 1 \\
2 & 0 & 0
\end{array}\right)\left(\begin{array}{l}
a_{s} \\
b_{s} \\
c_{s}
\end{array}\right)
$$

Expression (3), represents the approximate relation of the direction of the unit-cell vectors between sanidine and banalsite. The similarity in the cell dimensions between banalsite and sanidine can now be examined on the basis of atomic arrangement.

As mentioned earlier, the structure of banalsite can be looked upon as a stacking of a unit-layer generated by alternate stacking operations of mirror and glide. The structure of feldspar can be examined in a similar way. Fig. 6 shows, for example, a unit-layer of sanidine. The thickness of the layer is nearly the same as that of banalsite, but they are joined together, in the structure of sanidine, with adjacent layers by the operations about the two-fold axes in the boundaries of each layer. For the case of paracelsian (Smith, 1953, Bakakin and Belov, 1960), which is closely related to feldspars, the structure is made up of two analogous layers, which are not exactly identical, like the one shown in Fig. 7. However, for the structure of paracelsian, adjacent layers are related by mirror operations passing through apical oxygens if we assume complete $\mathrm{Al} / \mathrm{Si}$ disorder (Smith, 1953). Thus the stacking operations for these mineral species are summarized and compared below:

\begin{tabular}{cl}
\hline mineral species & stacking operations \\
\hline sanidine & 2 \\
paracelsian & (pseudo) $m$ \\
banalsite & $m$ and $n$ glide \\
\hline
\end{tabular}

Since all of these unit-layers are of similar dimensions, the unit cells of these minerals are similar except that the periodicity along the stacking direction of banalsite $\left(=c^{\prime}\right.$ axis) is twice those of the 
others. This is because, unlike the structure of sanidine and paracelsian, that of banalsite is based upon two kinds of stacking operations. In the structure of sanidine, the glide planes, with glide component parallel to the stacking direction $(=[\overline{100}])$, can also be considered, instead of the two-fold axes, as elements of the stacking operations. However, in the above list the operations are, for brevity, represented by two-fold rotations. In the feldspar structures having lower symmetry such as $P \overline{1}$, the inversions about the center of symmetry in the boundaries of unit layers play a role of stacking operations. The above way of looking at the structures thus explains the close similarity in the general building schemes of these minerals. However, a comparison of Fig. 5, Fig. 6 and Fig. 7, each giving respective unit-layer, shows an obvious difference in the configurations of the unit-layers. That of the banalsite unit-layer is especially different from the others. A marked difference is in the cofiguration of the four-membered rings. In contrast to those of sanidine or paracelsian, in which apices of adjacent pairs of tetrahedra point up or down with respect to the plane of projection (Figs. 6 and 7), the apices of tetrahedra in each ring of banalsite point up and down alternately (Fig. 5). And the unit-layers are, as a whole, less symmetrical than those of sanidine and paracelsian.

Such a difference in the configurations of four-membered rings gives rise to the following difference when layers are combined to form structures by stacking operations. If the layers, which consist of the rings of the sanidine or paracelsian types, are joined together by stacking operations, there are necessarily generated new fourmembered rings across the boundaries of the pairs of adjacent layers (Figs. 9 and 10). On the other hand, no additional four-membered rings are formed when stacking operations are applied to the banalsite layers (Fig. 8). This difference is solely due to the configuration characteristic of the four-membered rings of banalsite, with appices of opposite pairs of tetrahedra pointing up or down. It is 


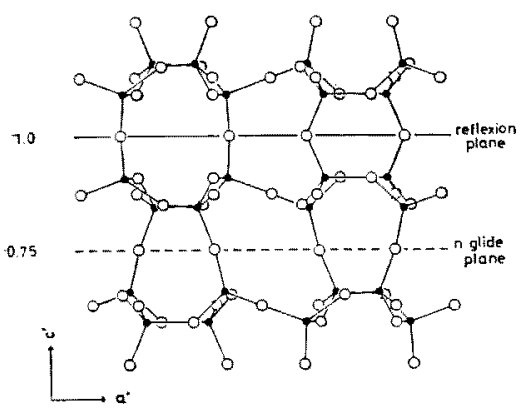

Fig. 8. The projection on the $\left(a^{\prime}, c^{\prime}\right)$ plane of banalsite. Open circles represent oxygen atoms and closed circles represent aluminum or silicon atoms. This projection is characteristic of six-membered rings only.

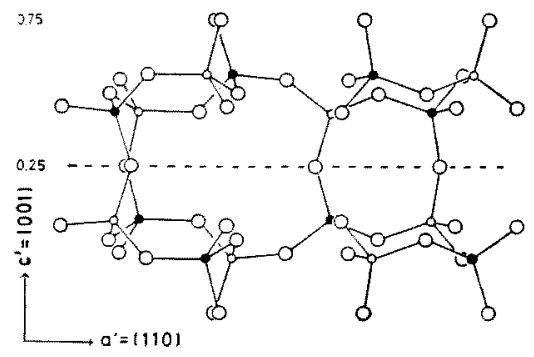

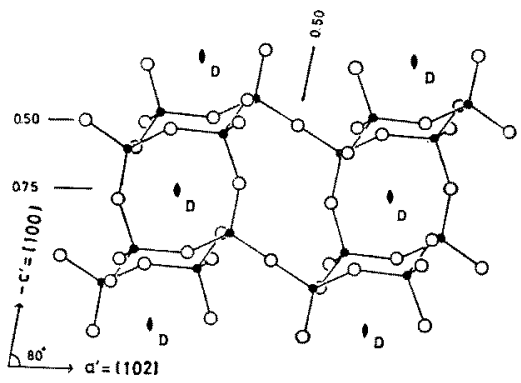

Fig. 9. The $b^{\prime}$-axis projection of sanidide. Open circles represent oxygen atoms and closed circles represent aluminum or silicon atoms. Four- and six-membered rings are seen in the figure. The four-membered rings are formed, across layer boundaries, by stacking operations indicated by $\mathrm{D}$.

Fig. 10. The projection on the $\left(a^{\prime}, c^{\prime}\right)$ plane of paracelsian. Large open circles represent oxygen atoms, and small open and closed circles represent silicon and aluminum rich $T$ atoms respectively. Four-and six-membered rings are seen like sanidine. The fourmembered rings are formed by stacking operations, mirror at $z^{\prime}=$ 0.25 indicated by broken line, if we neglect $\mathrm{Al} / \mathrm{Si}$ ordering.

to be noted that the four-membered rings of similar type have been found in the structure of scapolite (Pauling, 1930, Papike and Zoltai, 1965), which contains large $\mathrm{CO}_{3}$ groups or $\mathrm{Cl}$, in addition to cations like $\mathrm{Na}$ or $\mathrm{Ca}$ or both.

In conclusion, (1) the crystal structure of banalsite, $\mathrm{BaNa}_{2} \mathrm{Al}_{4} \mathrm{Si}_{4}$ $\mathrm{O}_{16}$, determined based upon intensity data obtained with the use of four-circle automatic diffractometer is similar to that of feldspar, 
from the viewpoint of a stacking of a unit-layer composed of fourand eight-membered rings of silicon and aluminum tetrahedra. However, the mutual orientation of the component tetrahedra and the way of connecting with the adjacent unit-layers are different from those in feldspar. (2) Although the mean T-O lengths of the two independent tetrahedra suggest that $\mathrm{Al}$ and $\mathrm{Si}$ atoms are distributed randomly over the tetrahedral sites, the structure of banalsite may be the result of a submicroscopic twinning of the structure in which the tetrahedral cations are completely ordered. (3) $\mathrm{Na}$ and $\mathrm{Ba}$ atoms are respectively coordinated by six and ten oxygen atoms. The mean $\mathrm{Na}-\mathrm{O}$ distance and that of $\mathrm{Ba}-\mathrm{O}$ are $2.501(6) \AA$ and $2.870(4) \AA$ respectively, and both are smaller than corresponding values in other alumino-silicates.

Acknowledgements-The auther wishes to express his sincere thanks to Professor Y. Takéuchi, for suggesting the problem and for his guidance throughout the work and for critical reading of the manuscript. He is indebted to Professor R. Sadanaga and $\mathrm{Dr}$. H. Takeda for their useful discussions. Thanks are also due to Prof. Y. Iitaka for making the automatic diffrctometer available for this study.

The universal crystallographic computation program system (UNICS) was used for some calculations in carrying the structure analysis into excution. The computations were performed on HITAC $5020 \mathrm{E}$ at the Computer Center of the University of Tokyo.

\section{REFERENCES}

Appleman, D. E. \& Clark, J. R. (1965) Amer. Miner., 50, 1827.

Bakakin, V. V. \& Belov, N. V. (1960) Kristallografiya, 5, 6, 864.

Busing, W. R., Martin, K. O. \& Levy, H. (1962) A Fortran crystallographic least-square program, ORFLS. ORNL-TM-305, Oak Ridge National Laboratory, Tennessee.

Hahn, T. \& Buerger, M. J. (1955) Zeits. Krist., 106, 308.

IITAKA, Y. (1953) Acta Cryst., 6, 663. 
Jones, J. B. (1968) Acta Cryst., B24, 355.

Karle, J. \& Karle, I. L. (1966) Acta Cryst., 21, 849.

Loewenstein, W. (1953) Amer. Miner., 39, 92.

Megaw, H. D., Kempster, C. J. E. \& Radoslovich, E. W. (1962) Acta Cryst., 15, 1017.

MeIer, W. M. (1960) Zeits. Krist., 113, 430.

Newnham, R. E. \& Megaw, H. D. (1960) Acta Cryst., 13, 303.

Papike, J. J. \& Zoltal, T. (1965) Amer. Miner., 50, 641.

Pauling, L. (1930) Proc. Acad. Sci., 16, 453.

Philips, M. W. \& Ribbe, P. H. (1973) Amer. Miner., 58, 263.

Ribbe, P. H., Megaw, H. D., Taylor, W.H., Ferguson, R. B. \& Traill, R. J. (1969) Acta Cryst., B25, 1503.

Sadanaga, R., Marumo, F. \& Takeuchi, Y. (1961) Acta Cryst., 14, 1153.

Smith, W. C., Bannister, F. A. \& Hey, M. H. (1944) Miner. Mag., 27, 33.

Sмiтh, J. V. (1953) Acta Cryst., 6, 613.

Smith, J. V. \& Bailey, S. W. (1963) Acta Cryst., 16, 801.

TAKEUCHI, Y. (1958) Miner. Journ., 2, 311.

TAKÉUChI, Y. (1972) Zeits. Krist., 135, 120.

TAKÉUChI, Y., KuDOH, Y. \& HaGA, N. (1973) Zeits. Krist., 136, 313.

TAKÉuch, Y., HaGA, N. \& ITO, J. (1973) Zeits. Krist., in press.

TAYLOR, W. H. (1933) Zeits. Krist., 85, 425.

WAINWRIght, J. E. \& StARKeY, J. (1971) Zeits. Krist., 133, 75.

Williams, P. P. \& Megaw, H. D. (1964) Acta Cryst., 17, 882.

Received June 30, 1973 